\title{
PENGARUH KARAKTERISTIK INOVASI DAN SISTEM SOSIAL TERHADAP TINGKAT ADOPSI TEKNOLOGI PENGELOLAAN TANAMAN TERPADU (PTT) PADI DI KECAMATAN KEBAKKRAMAT KABUPATEN KARANGANYAR
}

\section{THE INFLUENCE OF CHARACTERISTIC INNOVATION AND SOCIAL SYSTEM TOWARD THE ADOPTION RATE OF INTEGRATED CROP MANAGEMENT TECHNOLOGY OF RICE IN KEBAKKRAMAT SUB DISTRICT KARANGANYAR REGENCY}

\author{
Ardela Nurmastiti, Suminah, Agung Wibowo \\ Program Studi Penyuluhan dan Komunikasi Pertanian, Fakultas Pertanian, \\ Universitas Sebelas Maret \\ Jl.Ir.Sutami No.36 A Kentingan Surakarta 57126 Telp./Fax (0271) 637457 \\ Email: ardelanur@gmail.com/Telp.085728705987
}

\begin{abstract}
This study examines to find out the influence of characteristic innovation and social system toward the adoption rate of Integrated Crop Management (PTT) technology of rice in Kebakkramat Sub District Karanganyar Regency. The basic method of research is explanatory method with survey technique. The location of study was determined purposively in Kebakkramat Sub-district of Karanganyar Regency with the consideration that Kebakkramat Sub District is one of the subdistricts implementing Integrated Crop Management (PTT) program and the sub district has the lowest rice productivity among the two other sub districts namely Tasikmadu and Jaten Sub Districts implementing GP-PTT in Karanganyar Regency. The sampling method used is proportional random sampling, with a sample size of 60 farmers. Data analysis using path analysis. The results showed that: (1) there is significant influence between characteristic innovation, social system and motivation simultaneously toward adoption of integrated crop management innovation. (2) there is significant influence between characteristic innovation toward adoption of integrated crop management innovation greater if it is compared through motivation, there is significant influence between social system toward adoption of integrated crop management innovation greater if it is compared through motivation and there is significant influence between motivation to adoption of integrated crop management innovation.
\end{abstract}

Keywords: Characteristic Innovation, Integrated Crop Management, Social System

\section{Abstrak}

Penelitian ini bertujuan untuk mengetahui pengaruh karakteristik inovasi dan sistem sosial terhadap tingkat adopsi teknologi Pengelolaan Tanaman Terpadu (PTT) padi di Kecamatan Kebakkramat Kabupaten Karanganyar. Metode dasar 


\section{Jurnal Agritexts Volume 41 Nomer 2 Oktober 2017}

penelitian adalah metode eksplanatori dengan teknik survei. Lokasi penelitian ditentukan secara purposive di Kecamatan Kebakkramat Kabupaten Karanganyar dengan pertimbangan bahwa Kecamatan Kebakkramat adalah salah satu kecamatan yang menerapkan program Pengelolaan Tanaman Terpadu (PTT) dan kecamatan tersebut memiliki produktivitas padi terendah diantara kedua kecamatan lainnya yaitu Kecamatan Tasikmadu dan Kecamatan Jaten yang melaksanakan Program GP-PTT di Kabupaten Karanganyar. Metode pengambilan sampel yang digunakan adalah proportional random sampling, dengan jumlah sampel 60 petani. Analisis data menggunakan analisis jalur. Hasil penelitian menunjukkan bahwa: (1) terdapat pengaruh signifikan antara karakteristik inovasi, sistem sosial dan motivasi secara simultan terhadap adopsi inovasi pengelolaan tanaman terpadu. (2) terdapat pengaruh signifikan antara karakteristik inovasi terhadap adopsi inovasi pengelolaan tanaman terpadu secara langsung lebih besar jika dibandingkan melalui motivasi, sistem sosial berpengaruh signifikan terhadap tingkat adopsi teknologi pengelolaan tanaman terpadu secara langsung lebih besar jika dibandingkan melalui motivasi dan motivasi petani berpengaruh signifikan terhadap tingkat adopsi teknologi pengelolaan tanaman terpadu di Kecamatan Kebakkramat Kabupaten Karanganyar.

Kata Kunci: Karakteristik Inovasi, Pengelolaan Tanaman Terpadu (PTT), Sistem Sosial

\section{PENDAHULUAN}

Pembangunan pertanian pada dasarnya bertujuan untuk mewujudkan beberapa pencapaian utama yaitu terwujudnya sistem pertanian berdayasaing, tercapainya ketahanan pangan yang mandiri, dan terciptanya kesempatan kerja penuh bagi masyarakat pertanian. Pencapaian ketiga tujuan tersebut diharapkan dapat menghapus masyarakat pertanian dari lingkaran kemiskinan yang selama ini menjadi simpul kritis pembangunan nasional dan mengembangkan ekonomi kerakyatan yang berdaya saing global berbasis sumberdaya lokal (Dinas Pertanian Perkebunan dan Kehutanan, 2016). Namun, saat ini kondisi pertanian di Indonesia masih belum dapat mencukupi kebutuhan beras sendiri. Hal tersebut dikarenakan banyaknya konversi lahan pertanian menjadi kawasan industri dan banyaknya masyarakat yang telah meninggalkan sektor pertanian (Agrotani, 2016).

Sektor pertanian berperan penting dalam menyediakan bahan pangan bagi seluruh penduduk maupun menyediakan bahan baku bagi industri, dan untuk perdagangan ekspor (Suparta, 2010). Hal ini diawali dengan meningkatkan kualitas sumberdaya manusia yang baik, dimana setiap individu dalam rumah tangga mendapatkan asupan pangan dalam jumlah yang cukup, aman, dan bergizi secara berkelanjutan yang pada gilirannya akan meningkatkan 


\section{Nurmastiti, Suminah, Wibowom, Karakteristik Inovasi,,,}

status kesehatan dan memberikan kesempatan agar setiap individu mencapai potensi maksimumnya. Sejalan dengan hal tersebut, maka pada upaya peningkatan produksi padi difokuskan pada kawasan tanaman pangan, melalui Gerakan Penerapan Pengelolaan Tanaman Terpadu (GP-PTT) dengan fasilitasi bantuan sarana produksi (saprodi), tanam jajar legowo dan pertemuan kelompok pada seluruh areal program GP-PTT sebagai instrumen stimulan disertai dengan dukungan pembinaan, pengawalan dan pemantauan oleh berbagai pihak.

Kabupaten Karanganyar sendiri telah melaksanakan program Gerakan Penerapan Pengelolaan Tanaman Terpadu (GP-PTT) pada masa tanam kedua yang dilaksanakan di tiga kecamatan, yaitu Kecamatan Jaten, Kecamatan Tasikmadu dan Kecamatan Kebakkramat. Kecamatan Tasikmadu memiliki produktivitas 95,93 Kw/Ha, Kecamatan Jaten memiliki produktivitas sebesar 93,20 $\mathrm{Kw} / \mathrm{Ha}$ dan Kecamatan Kebakkramat memiliki produktivitas sebesar 90,98 $\mathrm{Kw} / \mathrm{Ha}$. Kecamatan Kebakkramat merupakan kecamatan yang memiliki produktivitas rendah, sehingga penting untuk dikaji mengenai pengaruh karakteristik inovasi dan sistem sosial terhadap adopsi teknologi Pengelolaan Tanaman Terpadu (PTT), sehingga dapat dikeetahui pengaruh karakteristik inovasi, sistem sosial dan motivasi terhadap adopsi inovasi pengelolaan tanaman terpadu.

\section{METODE PENELITIAN}

Metode dasar penelitian yang digunakan adalah metode eksplanatori dengan menggunakan teknik survei. Penentuan lokasi penelitian dilakukan secara sengaja (purposive) dengan memilih Kecamatan Kebakkramat Kabupaten Karanganyar, dimana kecamatan tersebut memiliki produktivitas padi terendah diantara kedua kecamatan lainnya yang melaksanakan Program GP-PTT di Kabupaten Karanganyar. Pengambilan sampel dengan cara proportional random sampling, yaitu petani di Desa Pulosari dan Desa Waru dengan jumlah responden sebesar 60 responden. Penelitian ini menggunakan data primer dengan menggunakan kuisioner sebagai alatnya dan data sekunder diperoleh dari instansi terkait.

Pengujian kuesioner penelitian dilakukan dengan uji validitas dan reliabilitas. Hasil uji validitas menunjukkan bahwa semua item pertanyaan pada variabel karakteristik inovasi, sistem sosial dan motivasi terhadap program Pengelolaan Tanaman Terpadu (PTT) mempunyai validitas yang tinggi. Hal tersebut dilihat berdasarkan nilai $r_{\text {hitung }}>r_{\text {tabel }}$ $(0,4438)$. Hasil uji reliabilitas juga menunjukkan nilai Cronbach alpha 


\section{Jurnal Agritexts Volume 41 Nomer 2 Oktober 2017}

adalah 0.984 yang artinya tingkat reliabilitasnya sangat tinggi.

Metode analisis data yang digunakan untuk mengetahui pengaruh antara karakteristik inovasi dan sistem sosial terhadap adopsi Pengelolaan Tanaman Terpadu (PTT) adalah analisis jalur, dimana data yang sebelumnya berupa data ordinal ditransformasikan terlebih dahulu menjadi data interval. Untuk menguji model analisis jalur dilakukan uji asumsi klasik yaitu uji normalitas dan uji heteroskedastisitas. Persamaan analisis jalur yang dipakai dalam penelitian ini adalah sebagai berikut:

$$
\begin{gathered}
Y 1=\rho y 1 x 1 X 1+\rho y 2 x 2 \times 2+ \\
p y 1 \varepsilon 1 \ldots .(1) \\
Y 2=\rho y 2 x 1 X 1+\rho y 2 x 2 X 2 \\
+\rho y 2 y 1 Y 1 \\
+\rho y 2
\end{gathered}
$$

Dimana:

$$
\begin{aligned}
& \text { X1 }=\text { Karakteristik Inovasi } \\
& \text { X2 }=\text { Sistem Sosial } \\
& \text { Y1 }=\text { Motivasi Petani } \\
& \text { Y2 = Adopsi Pengelolaan Tanaman } \\
& \quad \text { Terpadu } \\
& \rho=\text { Koefisien jalur } \\
& \text { e }=\text { Variabel residu }
\end{aligned}
$$

HASIL DAN PEMBAHASAN

Kecamatan Kebakkramat merupakan salah satu kecamatan yang berada di Kabupaten Karanganyar. Mata pencaharian penduduk sebagian besar masih sebagai petani meskipun tidak sebagai pekerjaan utama. Penggunaan lahan di Kecamatan Kebakkramat sebagian besar digunakan untuk menanam padi sebesar 57,84\% (Monografi Kecamatan Kebakkramat, 2016). Program GP-PTT dilaksanakan di tiga kecamatan yang mengikuti program tersebut, yaitu Kecamatan Tasikmadu, Kecamatan Jaten, dan Kecamatan Kebakkramat. Kecamatan Kebakkramat masih menerapkan program Pengelolaan Tanaman Terpadu (PTT) karena dengan menerapkan program tersebut dapat meningkatkan produktivitas padi.

\section{Karakteristik Inovasi}

Karakteristik inovasi adalah sifat atau karakter daripada inovasi program Pengelolaan Tanaman Terpadu (PTT). Karakteristik inovasi antara lain keuntungan relatif, kompatabilitas, kompleksitas, triabilitas, dan observabilitas. 
Nurmastiti, Suminah, Wibowom, Karakteristik Inovasi,,,

Tabel 1. Karakteristik Inovasi di Kecamatan Kebakkramat Kabupaten Karanganyar

\begin{tabular}{lccccc}
\hline \hline \multirow{1}{*}{ Keterangan } & \multicolumn{3}{c}{ Kategori } \\
\cline { 2 - 6 } & $\begin{array}{c}\text { Sangat } \\
\text { Rendah (\%) }\end{array}$ & Rendah (\%) & Sedang (\%) & Tinggi (\%) & $\begin{array}{c}\text { Sangat Tinggi } \\
(\%)\end{array}$ \\
\hline Keuntungan relatif & 0,00 & 25,00 & 56,67 & 18,33 & 0,00 \\
Kompatabilitas & 0,00 & 6,67 & 65,00 & 26,67 & 1,67 \\
Kompleksitas & 0,00 & 3,33 & 78,33 & 18,33 & 0,00 \\
Triabilitas & 0,00 & 10,00 & 43,33 & 35,00 & 11,67 \\
Observabilitas & 0,00 & 6,67 & 65,00 & $\mathbf{2 8 , 3 3}$ & 0,00 \\
\hline Karakteristik Inovasi & $\mathbf{0 , 0 0}$ & $\mathbf{0 , 0 0}$ & $\mathbf{8 6 , 6 7}$ & $\mathbf{1 3 , 3 3}$ & $\mathbf{0 , 0 0}$ \\
\hline \hline
\end{tabular}

Sumber: Analisis Data Primer, 2017

Sebagian besar petani responden cukup merasakan adanya keuntungan relatif dari program Pengelolaan Tanaman Terpadu dimana sebagian besar petani responden termasuk dalam kategori sedang. Keuntungan yang diperoleh dari penerapan program PTT antara lain yaitu dapat menambah relasi pertemanan dengan petani maupun penyuluh, petani juga dapat meningkatkan status sosial petani.

Kesesuaian (kompatabilitas) budidaya padi melalui program PTT termasuk dalam kategori sedang. Program PTT sesuai dengan pengalaman petani dengan masa lalu dimana sebelumnya Pengelolaan Tanaman Terpadu (PTT) sudah diperkenalkan terlebih dahulu. Pengenalan Pengelolaan Tanaman Terpadu (PTT) melalui sekolah lapang.

Tingkat kerumitan (kompleksitas) budidaya padi melalui program Pengelolaan Tanaman Terpadu (PTT) termasuk dalam kategori sedang. Kompleksitas dapat diukur dari tingkat persiapan lahan, penggunaan alat, dan pengelolaan budidaya.

Kemampuan ujicoba budidaya padi melalui program Pengelolaan Tanaman Terpadu (PTT) termasuk dalam kategori sedang. Petani dapat mencoba sendiri pada lahan pertanian secara luas dan hasil percobaannya lebih baik.

Sebagian besar petani responden menilai bahwa budidaya padi melalui program Pengelolaan Tanaman Terpadu (PTT) termasuk dalam kategori sedang. Hal tersebut dapat dilihat dari dapat diamatinya pertumbuhan padi dengan baik, petani dapat melihat data dan informasi keberhasilan Pengelolaan Tanaman Terpadu (PTT) dari media cetak maupun elektronik, petani dapat melihat keberhasilan Pengelolaan Tanaman Terpadu (PTT) dari petani itu sendiri. 


\section{Jurnal Agritexts Volume 41 Nomer 2 Oktober 2017}

Hasil dan Pembahasan Sistem Sosial

Sistem sosial adalah kumpulan unit yang berbeda secara fungsional dan terikat dalam kerjasama untuk memecahkan masalah dalam rangka mencapai tujuan bersama dari Pengelolaan Tanaman Terpadu (PTT).
Terdapat empat faktor yang memengaruhi proses keputusan inovasi dalam kaitannya dengan sistem sosial, antara lain struktur sosial, norma sistem, peran pemimpin dan agen perubahan.

Tabel 2. Sistem Sosial di Kecamatan Kebakkramat Kabupaten Karanganyar

\begin{tabular}{lccccc}
\hline \hline \multirow{2}{*}{ Keterangan } & \multicolumn{5}{c}{ Kategori } \\
\cline { 2 - 6 } & $\begin{array}{c}\text { Sangat } \\
\text { Rendah (\%) }\end{array}$ & Rendah (\%) & Sedang (\%) & Tinggi (\%) & $\begin{array}{c}\text { Sangat Tinggi } \\
(\%)\end{array}$ \\
\hline Struktur Sosial & 0,00 & 10,00 & 65,00 & 13,33 & 11,67 \\
Norma Sistem & 1,67 & 8,33 & 63,33 & 16,67 & 10,00 \\
Peran Pemimpin & 0,00 & 18,33 & 60,00 & 11,67 & 10,00 \\
Agen Perubahan & 0,00 & 5,00 & 58,33 & 20,00 & 16,67 \\
\hline Sistem Sosial & $\mathbf{0 , 0 0}$ & $\mathbf{0 , 0 0}$ & $\mathbf{6 6 , 6 7}$ & $\mathbf{1 8 , 3 3}$ & $\mathbf{1 5 , 0 0}$ \\
\hline \hline
\end{tabular}

Sumber: Analisis Data Primer, 2017

Petani responden merasakan bahwa struktur sosial sejalan program PTT dimana sebagian besar petani responden termasuk dalam kategori sedang. Adanya kelompok tani, petani dapat bertahan jika ada gangguan dari luar lingkungan, kelompok tani mampu mendorong dalam menyediakan sumberdaya dalam menerapkan program PTT, kelompok tani juga memberikan manfaat berupa informasi mengenai pertanian pada petani.

Petani merasakan bahwa program PTT ada yang sesuai dengan nilai dan norma yang dianut masyarakat dimana sebagian besar petani responden termasuk dalam kategori sedang. Dilihat dari program PTT sebagai pedoman dan pengen- dali aktivitas masyarakat, sebagai kekuatan untuk menjaga keutuhan masyarakat, dan dapat menjalin kerjasama antar masyarakat.

Petani responden menilai bahwa pemimpin atau ketua kelompok tani cukup berperan dalam proses adopsi PTT dimana sebagian besar petani responden termasuk dalam kategori sedang. Petani responden merasa bahwa ketua kelompok tani berperan dalam memberikan informasi, mempunyai perencanaan dan melakukan pengawasan.

Petani responden cukup merasakan adanya pengaruh agen perubahan dalam proses adopsi PTT dimana sebagian besar petani responden termasuk dalam kategori 
Nurmastiti, Suminah, Wibowom, Karakteristik Inovasi,,,

sedang. Hal tersebut dapat dilihat melalui keberhasilan perannya dalam hal membantu menyadarkan petani, mempengaruhi tingkah laku petani, serta dapat menjaga stabilitas agar inovasi tetap berlanjut.

Tabel 3. Motivasi Petani di Kecamatan Kebakkramat Kabupaten Karanganyar

\begin{tabular}{lccccc}
\hline \hline \multirow{2}{*}{ Keterangan } & \multicolumn{5}{c}{ Kategori } \\
\cline { 2 - 6 } & $\begin{array}{c}\text { Sangat } \\
\text { Rendah (\%) }\end{array}$ & Rendah (\%) & Sedang (\%) & Tinggi (\%) & $\begin{array}{c}\text { Sangat } \\
\text { Tinggi (\%) }\end{array}$ \\
\hline Motivasi Ekonomis & 0,00 & 6,67 & 56,67 & 36,67 & 0,00 \\
Motivasi Psikologis & 0,00 & 6,67 & 58,33 & 35,00 & 0,00 \\
Motivasi Sosiologis & 0,00 & 10,00 & 48,33 & 41,67 & 0,00 \\
\hline Motivasi & $\mathbf{0 , 0 0}$ & $\mathbf{0 , 0 0}$ & $\mathbf{8 0 , 0 0}$ & $\mathbf{2 0 , 0 0}$ & $\mathbf{0 , 0 0}$ \\
\hline \hline
\end{tabular}

Sumber: Analisis Data Primer, 2017

\section{Motivasi}

Motivasi adalah dorongan, tekanan yang menyebabkan seseorang untuk melakukan sesuatu kegiatan. Motivasi dalam penelitian ini meliputi kebutuhan ekonomis, kebutuhan psikologis dan kebutuhan sosiologis. Sebagian besar petani menganggap bahwa kebutuhan ekonomis petani termasuk dalam kategori sedang. Hal ini dilihat dari penerapan Pengelolaan Tanaman Terpadu (PTT) yang dapat memperoleh pendapatan lebih, hidup lebih sejahtera atau lebih baik dari sebelumnya, dan dapat memiliki tabungan serta meningkatkan tabungan petani. Sebagian besar petani menganggap bahwa kebutuhan psikologis petani termasuk dalam kategori sedang. Jika kebutuhan psikologis terpenuhi maka akan mendorong petani untuk menerapkan program Pengelolaan Tanaman Terpadu (PTT). Hal ini diketahui dari diakuinya oleh masyarakat lain, dihargai dan dapat menyesuaikan diri dengan lingkungannya. Sebagian besar petani menganggap bahwa .

Tabel 4. Tingkat Adopsi Inovasi Pengelolaan Tanaman Terpadu (PTT) di Kecamatan Kebakkramat Kabupaten Karanganyar

\begin{tabular}{lccccc}
\hline \hline \multirow{2}{*}{ Keterangan } & \multicolumn{5}{c}{ Kategori } \\
\cline { 2 - 6 } & $\begin{array}{c}\text { Sangat } \\
\text { Rendah (\%) }\end{array}$ & $\begin{array}{c}\text { Rendah } \\
(\%)\end{array}$ & $\begin{array}{c}\text { Sedang } \\
(\%)\end{array}$ & Tinggi (\%) & $\begin{array}{c}\text { Sangat } \\
\text { Tinggi (\%) }\end{array}$ \\
\hline Varietas Unggul & 11,67 & 16,67 & 60,00 & 0,00 & 11,67 \\
Benih Bermutu dan Berlabel & 5,00 & 20,00 & 0,00 & 60,00 & 15,00 \\
Pengaturan Posisi Tanam & 10,00 & 23,33 & 0,00 & 48,33 & 18,33 \\
Pemupukan & 0,00 & 16,67 & 33,33 & 45,00 & 21,67 \\
Pengendalian OPT dengan & 6,67 & 20,00 & 0,00 & 65,00 & 25,00 \\
Pendekatan PHT & & & & & $\mathbf{3 , 3 3}$ \\
\hline Adopsi PTT & $\mathbf{0 , 0 0}$ & $\mathbf{5 , 0 0}$ & $\mathbf{4 0 , 0 0}$ & $\mathbf{5 1 , 6 7}$ \\
\hline \hline
\end{tabular}

Sumber: Analisis Data Primer, 2017 


\section{Jurnal Agritexts Volume 41 Nomer 2 Oktober 2017}

Sebagian besar petani menilai bahwa penggunaan varietas unggul dalam penerapan PTT termasuk dalam kategori sedang. Petani menggunakan varietas yang sesuai dengan kondisi lingkungannya karena jika varietas tersebut sesuai maka hasil produksi padi akan meningkat. Varietas yang digunakan juga sesuai dengan keinginan pasar kebutuhan sosiologis petani termasuk dalam kategori sedang. Hal ini dapat dilihat dari dengan menerapkan inovasi Pengelolaan Tanaman Terpadu (PTT) petani bekerjasama dengan sesama petani, petani dapat bergabung dengan kelompok tani dan petani memiliki lebih banyak teman.

\section{Tingkat Adopsi Inovasi Pengelolaan Tanaman Terpadu (PTT)}

Tingkat adopsi pengelolaan tanaman terpadu adalah tingkat penerapan dari komponen Pengelolaan Tanaman Terpadu (PTT). Komponen dari Pengelolaan Tanaman Terpadu (PTT) antara lain varietas unggul, benih bermutu dan berlabel, pengaturan posisi tanaman secara optimum, pemupukan, dan pengendalian OPT dengan PHT.

karena akan mempermudah pemasaran dan penjualan hasil produksi padi tersebut.

Sebagian besar petani responden menilai bahwa penggunaan benih bermutu dan berlabel termasuk dalam kategori tinggi. Banyak petani yang melakukan pemilihan benih dengan baik, yaitu dengan cara merendam benih dalam larutan $20 \mathrm{gr}$ ZA/liter atau larutan garam 20 gr/liter air, menggunakan abu dalam perendaman, kemudian benih akan terangkat dan membuang benih yang mengambang/mengapung.

Sebagian besar petani responden menilai bahwa pengaturan posisi tanam secara optimum termasuk dalam kategori tinggi. Dimana petani responden telah menerapkan jumlah bibit yang ditanam tidak lebih dari 3 bibit tiap rumpun, jarak tanam yang digunakan jajar legowo (2:1 atau 4:1) dan menyediakan ruang kosong untuk pengaturan air.

Sebagian besar petani responden menilai bahwa pemberian pupuk dalam penerapan Pengelolaan Tanaman Terpadu (PTT) termasuk dalam kategori sedang. Pemupukan N berdasarkan BWD yaitu pemupukan $\mathrm{N}$ berdasarkan BWD sesuai waktu tetap. Petani responden juga telah memberikan pupuk $\mathrm{P}$ dan $\mathrm{K}$ berdasarkan status hara tanah sesuai dengan rekomendasi program Pengelolaan Tanaman Terpadu (PTT).

Sebagian besar petani responden menilai bahwa pengendalian OPT dengan pendekatan PHT termasuk dalam kategori tinggi. Dimana banyak petani yang sudah menerapkan hampir seluruh komponen dalam pengendalian OPT tersebut. Adapun cara-cara pengendaliaan 
Nurmastiti, Suminah, Wibowom, Karakteristik Inovasi,,,

yang telah diterapkan oleh petani adalah membasmi hama tikus bersama petani lain (gropyokan), membasmi hama wereng coklat dengan cara pengendalian mulai dari penyiapan lahan, membasmi penggerek batang padi dengan insektisida dan mengendalikan hama keong mas pada pratanam dan setelah panen serta pada fase stadia vegetatif maupun generatif.

\section{Pengaruh Karakteristik Inovasi dan} Sistem Sosial terhadap Tingkat Adopsi Inovasi Pengelolaan Tanaman Terpadu (PTT)

Penelitian ini dilakukan untuk mengetahui pengaruh antara karakteristik inovasi dan sistem sosial terhadap tingkat adopsi inovasi Pengelolaan Tanaman Terpadu (PTT). Analisis jalur digunakan untuk mengetahui pengaruh antara karakteristik inovasi dan sistem sosial terhadap tingkat adopsi. Berdasarkan hasil uji asumsi klasik menunjukkan bahwa tidak terdapat gangguan heteroskedastisitas pada model analisis jalur dan data berdistribusi normal. Berikut merupakan persamaan analisis jalur tingkat adopsi inovasi:

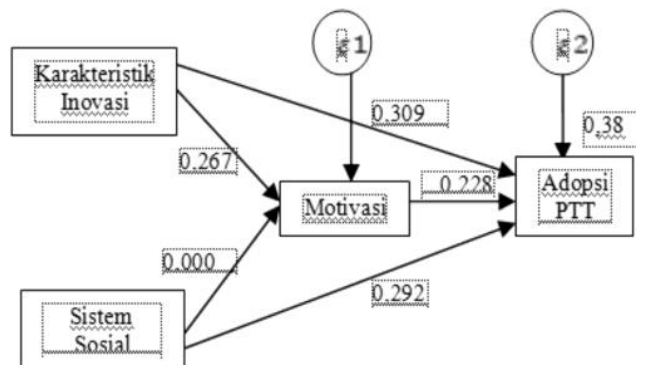

Gambar 2. Hasil Model Persamaan Analisis Jalur

Berdasarkan hasil analisis jalur, menunjukkan bahwa variabel independen dapat menjelaskan variabel dependen sebesar 38\%, sedangkan sisanya (62\%) diterangkan oleh faktor lain yang tidak diteliti seperti saluran komunikasi, jenis keputusan inovasi dan kualifikasi atau keadaan penyuluh.

Tabel 5. Koefisien Analisis Jalur Adopsi Karakteristik Inovasi dan Sistem Sosial terhadap Penerapan Adopsi Inovasi PTT

\begin{tabular}{llccl}
\hline \hline & Variabel & C.R. & P & Keterangan \\
\hline Motivasi & $\leftarrow$ Karakteristik Inovasi & 2,067 & 0,039 & Signifikan \\
Motivasi & $\leftarrow$ Sistem Sosial & 0,002 & 0,998 & Tidak Signifikan \\
Adopsi PTT & $\leftarrow$ Sistem Sosial & 2,555 & 0,011 & Signifikan \\
Adopsi PTT & $\leftarrow$ Karakteristik Inovasi & 2,615 & 0,009 & Signifikan \\
Adopsi PTT & $\leftarrow$ Motivasi & 1,977 & 0,048 & Signifikan \\
\hline \hline
\end{tabular}

Sumber: Analisis Data Primer, 2017 


\section{Jurnal Agritexts Volume 41 Nomer 2 Oktober 2017}

Berdasarkan Tabel 4, karakteristik inovasi $\left(\mathrm{X}_{1}\right)$ secara parsial berpengaruh signifikan terhadap motivasi $\left(Y_{1}\right)$. Artinya semakin tinggi karakteristik inovasi Pengelolaan Tanaman Terpadu (PTT) maka tingkat motivasi petani akan semakin tinggi. Hasil penelitian sesuai dengan penelitian Zulvera (2014), yaitu karakteristik inovasi berpengaruh signifikan terhadap motivasi petani.

Sistem sosial $\left(\mathrm{X}_{2}\right)$ secara parsial tidak berpengaruh signifikan terhadap motivasi $\left(Y_{1}\right)$. Hal ini berarti bahwa sistem sosial tidak berpengaruh signifikan terhadap motivasi petani dengan tingkat kepercayaan $95 \%$. Tinggi rendahnya sistem sosial program pengelolaan tanaman terpadu (PTT) yang dirasakan oleh petani tidak memberikan perubahan pada motivasi petani. Petani tidak memiliki motivasi ekonomis dimana petani kurang ingin jika menerapkan inovasi Pengelolaan Tanaman Terpadu (PTT) adalah untuk memenuhi kebutuhannya karena kebutuhan petani sudah terpenuhi dari pekerjaan utamanya. Petani juga tidak memiliki keinginan untuk memenuhi kebutuhan psikologis dimana dengan menerapkan inovasi Pengelolaan Tanaman Terpadu (PTT) tidak akan meningkatkan status sosial petani dalam masyarakat. Selain itu, petani tidak memiliki keinginan dalam kebutuhan sosio- logis, dimana interaksi antar petani dalam masyarakat kurang, karena pekerjaan petani sebagai karyawan pabrik membuat petani jarang bertemu dan jarang berinteraksi dengan petani lain. Kegiatan gotongroyong antar petani juga kurang, dimana petani memiliki sifat individualis dan kurang berinteraksi dengan orang lain dikarenakan letak pertanian disekitar wilayah perkotaan.

Karakteristik inovasi $\left(\mathrm{X}_{1}\right)$ secara parsial berpengaruh signifikan terhadap respons petani dengan tingkat adopsi PTT. Semakin tinggi karakteristik inovasi Pengelolaan Tanaman Terpadu (PTT) maka tingkat adopsi inovasi Pengelolaan Tanaman Terpadu (PTT) akan semakin tinggi. hal tersebut sejalan dengan pendapat Rogers (1995), bahwa adopsi inovasi dapat diukur dengan beragam tolak ukur (indikator) dan ukuran. Setiap sifat secara empiris mungkin saling berhubungan sama lain tetapi secara konseptual mereka itu berbeda. Kelima sifat itu adalah keuntungan relatif, kesesuaian, kerumitan, dapat dicobakan dan dapat diamati.

Sistem sosial $\left(\mathrm{X}_{2}\right)$ secara parsial berpengaruh signifikan terhadap tingkat adopsi PTT. Tinggi rendahnya sistem sosial program pengelolaan tanaman terpadu (PTT) yang dirasakan oleh petani akan memberikan perubahan pada adopsi pengelolaan 
Nurmastiti, Suminah, Wibowom, Karakteristik Inovasi,,,

tanaman terpadu (PTT). Semakin tinggi sistem sosial Pengelolaan Tanaman Terpadu (PTT) maka tingkat adopsi inovasi Pengelolaan Tanaman Terpadu (PTT) akan semakin tinggi. Penelitian ini juga mendukung pendapat Rogers (1995), bahwa sistem sosial dapat memfasilitasi atau menghambat difusi inovasi dalam suatu sistem, hal ini sangat berhubungan dengan derajat keserasian (compatibility) inovasi dengan nilai atau kepercayaan masyarakat dalam suatu sistem sosial. Jadi, derajat ketidaksesuaian suatu inovasi dengan kepercayaan

Tabel 6. Efek Terstandarisasi Antar Variabel

\begin{tabular}{lccc}
\hline \hline \multicolumn{1}{c}{ Variabel } & Pengaruh Langsung & Pengaruh Tidak Langsung & Total Pengaruh \\
\hline Karakteristik Inovasi & 0,309 & 0,061 & 0,370 \\
Sistem Sosial & 0,292 & 0,000 & 0,292 \\
Motivasi & 0,228 & 0,000 & 0,228 \\
\hline \hline
\end{tabular}

Sumber: Analisis Data Primer, 2017

Berdasarkan Tabel 5, dapat diketahui bahwa karakteristik inovasi secara langsung mempengaruhi adopsi inovasi PTT. Sistem sosial secara langsung juga mempengaruhi adopsi inovasi PTT. Selain itu, motivasi mempengaruhi adopsi inovasi PTT secara langsung. Pengaruh tidak langsung dari karakteristik inovasi melalui motivasi kurang mempengaruhi adopsi inovasi lebih besar 0,061 daripada pengaruh langsung.

Pengelolaan Tanaman Terpadu (PTT), tetapi memiliki total pengaruh Sistem sosial juga mempunyai atau nilai-nilai yang dianut oleh individu (sekelompok masyarakat) dalam suatu sistem sosial berpengaruh terhadap penerimaan suatu inovasi tersebut.

Motivasi $\left(Y_{1}\right)$ secara parsial berpengaruh signifikan terhadap tingkat adopsi PTT. Tinggi rendahnya motivasi petani dalam program pengelolaan tanaman terpadu (PTT) yang dirasakan oleh petani akan memberikan perubahan pada adopsi pengelolaan tanaman terpadu (PTT). Semakin tinggi motivasi petani dalam program Pengelolaan Tanaman Terpadu (PTT) maka tingkat adopsi inovasi Pengelolaan Tanaman Terpadu (PTT) akan semakin tinggi.

\section{Efek Langsung, Tidak Langsung dan Total Pengaruh}

pengaruh secara tidak langsung melalui motivasi, tetapi total pengaruh tidak menunjukkan penguatan 0,000 . Motivasi juga mempunyai pengaruh langsung terhadap adopsi inovasi PTT, tetapi total pengaruh tidak menunjukkan penguatan 0,000.

Pengaruh tidak langsung karakteristik inovasi dan sistem sosial 


\section{Jurnal Agritexts Volume 41 Nomer 2 Oktober 2017}

melalui motivasi tidak lebih besar daripada pengaruh langsung. Hal ini dikarenakan pertanian bukan merupakan mata pencaharian utama di Kecamatan Kebakkramat. Petani hanya menerapkan program baru dari pemerintah. Motivasi petani meliputi motivasi ekonomis, motivasi psikologis dan motivasi sosiologis. Terkait dengan motivasi ekonomis, petani sudah mampu mencukupi kebutuhan sehari-hari, pertanian hanya merupakan mata pencaharian tambahan, serta jika pertanian mengalami gagal panen maka petani tidak khawatir karena petani sudah memiliki penghasilan dari mata pencaharian utama. Pekerjaan utama masyarakat di Kecamatan Kebakkramat adalah karyawan pabrik dimana pekerjaan tersebut memiliki penghasilan tetap dan mencukupi kebutuhan sehari-hari masyarakat. Petani menerapkan inovasi PTT bukan karena ingin mendapat keuntungan atau penghasilan yang lebih dari cukup untuk memenuhi kebutuhan hidupnya. Mengenai hasil dari penerapan inovasi PTT, petani juga tidak mengalami kekhawatiran jika mengalami gagal panen atau hasilnya tidak sesuai dengan keinginan petani, karena pertanian hanya sebagai mata pencaharian tambahan.

Terkait dengan kebutuhan psikologis, petani sudah memperoleh status sosial dan diakui oleh masyarakat lain dengan atau tanpa menerapkan program PTT. Adanya pencaharian tetap dari masyarakat di Kecamatan Kebakkramat, petani tidak khawatir mengenai status sosialnya dalam masyarakat. Hal tersebut dikarenakan petani telah memperoleh status sosialnya masing-masing, dimana dengan menerapkan atau tidak menerapkan inovasi PTT petani tidak dapat meningkatkan status sosialnya.

Terkait dengan kebutuhan sosiologis, karena pertanian terletak diwilayah perkotaan maka petani memiliki sifat individualis serta tidak semua masyarakat di Kecamatan Kebakkramat merupakan petani sehingga rasa gotong royong antar petani kurang. Pekerjaan petani sebagai karyawan membuat intensitas pertemuan antar petani menjadi kurang, dimana interaksi antar petani juga kurang. Letak pertanian yang di daerah perkotaan juga membuat rasa individualis antar petani juga tinggi. Sehingga, rasa gotong-royong antar petani dalam hal saling membantu dalam bidang pertanian semakin kurang.

\section{KESIMPULAN DAN SARAN \\ Kesimpulan}

Hasil penelitian menunjukkan bahwa karakteristik inovasi, sistem sosial dan motivasi petani secara simultan berpengaruh signifikan terhadap tingkat adopsi teknologi 
Nurmastiti, Suminah, Wibowom, Karakteristik Inovasi,,,

pengelolaan tanaman terpadu di Kecamatan Kebakkramat Kabupaten Karanganyar. Secara parsial karakteristik inovasi berpengaruh signifykan terhadap tingkat adopsi teknologi pengelolaan tanaman terpadu secara langsung lebih besar jika dibandingkan melalui motivasi. Sistem sosial berpengaruh signifikan terhadap tingkat adopsi teknologi pengelolaan tanaman terpadu secara langsung lebih besar jika disbandingkan melalui motivasi. Motivasi petani berpengaruh signifikan terhadap tingkat adopsi teknologi pengelolaan tanaman terpadu di Kecamatan Kebakkramat Kabupaten Karanganyar.

\section{Saran}

Adapun saran yang dapat digunakan sebagai pertimbangan bagi pihak terkait antara lain, terkait dengan karakteristik inovasi, sebaiknya inovasi baru lebih memberikan keuntungan bagi petani, lebih sesuai dengan keadaan petani dan pertanian, lebih mudah dalam penerapan, lebih mudah diujicoba, dan lebih mudah diamati supaya petani menerapkan inovasi baru. Terkait dengan sistem sosial, walaupun masyarakat sudah memiliki penghasilan dari luar pertanian sebaiknya masyarakat tetap memperrhatikan inovasi jika inovasi tersebut bermanfaat. Terkait penelitian selanjutnya dapat dikaji mengenai faktor lain yang berpengaruh dalam suatu adopsi inovasi, yaitu saluran komunikasi, jenis keputusan inovasi, proses penyuluhan yang terkait dengan penggunaan media, metode dan teknik penyuluhan serta kredibilitas penyuluh.

\section{DAFTAR PUSTAKA}

Agrotani. 2016. Pertanian Indonesia Tahun 2016. http://www.agro tani.com/pertanian-indonesiatahun-2016/. Diakses pada tanggal 11 Oktober 2016.

Badan Litbang Pertanian. 2015. Kebutuhan Beras Nasional. http://www.litbang.pertanian.g o.id/ks/one/758/. Diakses pada tanggal 12 Oktober 2016.

Bakri, Saepudin. 2015. Cegah Stunting, Langkah Awal Meningkatkan Kualitas SDM. http://mcaindonesia.go.id/kabar-kami/ cegah-stunting-langkah-awalmeningkatkan-kualitas-sdm/.

Diakses pada tanggal 20 Oktober 2016.

Badan Pusat Statistik. 2013. Statistik Penggunaan Lahan. http:// www.bps.go.id. Diakses pada tanggal 17 Desember 2016.

Dinas Pertanian Pekebunan dan Kehutanan. 2016. Rencana Kerja Dinas Pertanian Perkebunan dan Kehutanan Tahun 2016. Bandung: Dinas Pertanian Perkebunan dan Kehutanan. 
Jurnal Agritexts Volume 41 Nomer 2 Oktober 2017

Laoli, Novelinus. 2016. Mendag: Zulvera. 2014. Faktor Penentu Adopsi Kebutuhan Beras Baru TerpeSistem Pertanian Sayuran Orgahuni 95\%. http://m.kontan.co id/news/mendag-kebutuhanberas-baru-terpenuhi-95. Diakses pada tanggal 12 Oktober 2016.

Rogers, Everett, M.. 1995. Diffution nik Dan Keberdayaan Petani Di Provinsi Sumatera Barat. (Disertasi). Program Studi IImu Penyuluhan Pembangunan. Bogor: Sekolah Pascasarjana of Innovation fourth Edition. New York: The Free Press.

Suparta, Nyoman. 2010. Memantapkan Strategi Pengelolaan Pertanian. Denpasar: Pustaka Nayottama. 